\title{
Investment Decisions and Socio-demographic Characteristics - Empirical Evidence from Germany
}

\author{
Tristan Nguyen ${ }^{1} \&$ Alexander Schüßler ${ }^{2}$ \\ ${ }^{1}$ WHL Graduate School of Business and Economics, Lahr, Germany \\ ${ }^{2}$ HHL Leipzig Graduate School of Management, Leipzig, Germany \\ Correspondence: Tristan Nguyen, Department of Economics/Insurance and Health Economics, WHL Graduate \\ School of Business and Economics, Hohbergweg 15-17, D-77933 Lahr, Germany. Tel: 49-78-2192-3865. E-mail: \\ tristan.nguyen@whl-lahr.de
}

Received: June 2, 2012

Accepted: June 19, $2012 \quad$ Online Published: July 19, 2012

doi:10.5539/ijef.v4n9p1

URL: http://dx.doi.org/10.5539/ijef.v4n9p1

\begin{abstract}
Financial decisions are influenced by psychological factors. Investors make typical mistakes which are well-documented in the literature. To test these mistakes we conduct a survey among German individual investors. Moreover we analyze whether socio demographic attributes experience, education and income affect behavior. The study shows that systematic mistakes are prevalent among German investors: they act according to the Self-Attribution Bias and the Endowment Effect. They overweight domestic stocks and anchor their decisions on irrelevant information. Representativeness and Herd Behavior is also prevalent. Among tested characteristics, education best predicts investor behavior. A higher level of education reduces Self-Attribution Bias, Anchoring and Representativeness significantly.
\end{abstract}

Keywords: behavioral finance, investment decisions, socio-demographic characteristics, German stock market, irrationality

\section{Introduction}

A main assumption of traditional financial market theory is that market participants are rational. Several studies show that investor behavior is not always rational. In fact sometimes it is actually systematically irrational. Investors make typical mistakes which are well-documented in the literature, some of which are introduced in this article. At this juncture the existing literature is reviewed and the explained mistakes are analyzed empirically for German individual investors. Traditionally, German companies are financed predominantly by banks. Thus the German equity culture is less developed than the equity culture in the US, the UK or other Anglo-Saxon countries. In 2010 only $5.3 \%$ of Germans invested in equities. In the USA and the UK for comparison, $25.4 \%$ and $23.0 \%$ of the population invested in equities (Deutsches Aktieninstitut, 2011). Therefore it is interesting to know whether behavioral differences exist between German investors and investors of more developed financial markets. This empirical study asks two questions:

a) Do German individual investors behave according to typical mistakes?

b) Do behavioral differences exist between various socio-demographic groups in Germany?

Among the socio-demographic characteristics studied are experience, education level and gross annual income of an individual. This paper describes how these characteristics influence the investment behavior of individuals. We expect that people with higher experience, education level and gross annual income are less inclined to make the described mistakes.

\section{Literature Review and Hypotheses}

\subsection{Self-attribution Bias}

Self-Attribution Bias reveals that people interpret success and failure differently: Individuals tend to attribute success to their own abilities. In contrast failure is often attributed to external factors which they cannot influence (Miller \& Ross, 1975). Therefore, people typically do not learn from their mistakes because they actually are not aware of those mistakes or do not remember them. Lau and Russell (1980) study Self-Attribution Bias for athletes and their managers. They find that athletes and their managers credit $80 \%$ of the victories of 
their own team to internal factors. Internal factors are linked to the achievement and capabilities of their own team. On the other hand, losses are explained by internal factors in only $53 \%$ of cases. Instead, external reasons, such as referees' decisions or the weather, are often blamed for defeats. Additionally, Lau and Russell study the explanations given by journalists in newspapers. In the case of a victory, journalists attribute success $70 \%$ of the time to internal factors. Yet, journalists attribute only $57 \%$ of defeats to internal factors. Thus, journalists explain success more often by internal factors than failure, as well, yet the Self-Attribution Bias of journalists is weaker than that of athletes or managers.

Choi and Dong (2008) study Self-Attribution Bias in financial markets. They conclude that institutional investors attribute success to their own abilities whereas failure is typically explained by external factors. Choi and Dong document that in case of success, investors become overconfident. Overconfidence leads to investing in industries which are not in the circle of competence of those investors. Doukas and Petmezas (2007) also find a relationship between Self-Attribution Bias and Overconfidence for institutional investors. Overconfidence leads to excessive trading, which is responsible for poor investment results (Doukas \& Petmezas, 2007).

This article studies Self-Attribution Bias. Because of the results of former research we expect that investors act according to the Self-Attribution Bias.

\section{H1.1: Investors explain good results by their own abilities whereas bad results by bad luck.}

H1.2: Self-Attribution Bias decreases with the increasing experience, education level and gross annual income of a person.

\subsection{Equity Home Bias}

Familiarity plays a role in decision making. Having the choice between two risky bets in which the odds are the same, individuals prefer the more familiar one. Often they actually prefer the more familiar bet even if the odds are lower than for the alternative (Heath \& Tversky, 1991). This pattern is also prevalent in the stock market, where investors prefer familiar stocks to less familiar stocks (Huberman, 2001). They obviously feel better when they know the company they are investing in (Nofsinger, 2011). Mostly investors are more familiar with companies which are located in their home countries than with companies from abroad, therefore they typically overweight domestic stocks. This behavior is not consistent with the idea of optimal diversification in financial market theory. In fact, international diversification enhances risk-adjusted returns because it reduces the importance of national factors like political decisions, country-specific industry structures or national interest rates. Investors prefer domestic stocks because they typically have more confidence in domestic markets than in foreign markets. If investors in spite of this decide to buy foreign stocks, they prefer to invest in global companies which are internationally known. Those companies are mostly large companies with revenues all over the world (Kang \& Stulz, 1997). Moreover, investors prefer stocks in countries which are culturally similar or lie next to the home country of the investor (Chan, Covrig \& Ng, 2005).

The Equity Home Bias is prevalent in different countries. Strong and Xu (2003) find the Equity Home Bias for the USA, Japan and several European countries. We expect German investors to act accordingly.

\section{H2.1: German investors overweight German stocks.}

H2.2. The Equity Home Bias decreases with the increasing experience, education level and gross annual income of a person.

\subsection{Endowment Effect}

The Endowment Effect states that the relationship people have to an object plays a role in valuing the object: People value an object more highly if they own it. Therefore, in a negotiation the asking price is often higher than the fair value. The Endowment Effect influences investment decisions. To study the Endowment Effect, Samuelson and Zeckhauser (1988) confronted test persons with the situation of a major inheritance. They told participants that the inheritance would be completely in one asset class. For each person the asset classes were different. Afterwards, participants should redistribute the assets. The resulting redistribution depended heavily upon the original distribution. Asset classes in which the sum had been originally invested were overweighted. The Endowment Effect was stronger when subjects were offered several possibilities to reinvest the money. Obviously, a high complexity of the situation increases the tendency to copy the original distribution.

We expect German investors to act according to the Endowment Effect.

\section{H3.1: Investors value an object more highly if they own it.}

H3.2: The Endowment Effect decreases with the increasing experience, education level and gross annual income of a person. 


\subsection{Anchoring}

Anchoring means that people who make decisions under uncertainty are influenced by additional information. This holds true even when the information obviously has no relevance. The decision maker anchors on the information and adjusts his or her response as a result. Hence the anchor is a reference point which influences the decision although it does not have any explanatory value. Tversky and Kahneman (1974) study Anchoring in an experiment. They asked questions about general knowledge, which could be answered with a specific figure. Before individuals were able to answer, a wheel of fortune with figures form 1 to 100 was turned. The wheel was manipulated so that the result was either 10 or 65 . After the wheel was turned participants were asked whether their answer was either higher or lower than the figure on the wheel of fortune. Afterwards test persons should give a precise estimate. Tversky and Kahneman find that estimates depend strongly upon the result of the wheel of fortune. Participants, who were confronted with the number 10 chose an average number of 25 whereas participants who were confronted with 65 chose an average number of 45 . This study shows how people are influenced in their decision making by irrelevant information like the result of a wheel of fortune.

Anchoring also plays a role when investors form expectations about future returns. He and Shen (2009) show that there is a relation between past market returns and expected returns. Past returns serve as an anchor for expected returns. This result holds for single shares and the stock market.

These findings lead to the expectation that Anchoring plays a role for German individual investors, too.

\section{H4.1: Irrelevant information influences investors.}

H4.2: Anchoring decreases with the increasing experience, education level and gross annual income of a person.

\subsection{Representativeness}

Representativeness is a heuristic. By using Representativeness, individuals estimate the probability that an event belongs to a population based on whether the event is representative for the population (Tversky \& Kahneman, 1974). People estimate that things which look similar are in fact similar (Nofsinger, 2011). Heuristics can make sense because estimates are fast and not very complex. But they can also lead to systematic mistakes: the possibility that an event belongs to a population is typically overestimated in case the event is representative for the population. Tversky and Kahneman (1974) find that people make these kinds of mistakes when they use Representativeness.

Representativeness leads individuals to assume interrelations exist when there are actually no interrelations. It is therefore responsible for a multitude of mistakes. For example, forecasts of economic activity are often made because of similarities with former developments. The possibility that such similarities are pure chance is often not considered. We test if investors are influenced by Representativeness.

\section{H5.1: Investors estimate probabilities incorrectly because of Representativeness.}

H5.2: Representativeness decreases with the increasing experience, education level and gross annual income of a person.

\subsection{Herd Behavior}

Several studies show that people are influenced by other people. For example, individuals often imitate the behavior of a group because of social pressure: It can be displeasing to be seen as not normal or as an outsider. (Asch, 1952) Nevertheless, even if decisions are anonymous people join the majority. Thus, social pressure cannot be the reason in these cases. Here behavior is explained by the tendency to trust the majority (Milgram, 1974). People assume that the probability of a large group being at fault is marginal. Both factors seem to play a role in group conformity behavior: the fact that individuals do not want to be isolated and the belief that a large number of people cannot err. Group conformity behavior is especially problematic if one's own analysis is completely surrendered for the strong belief in the opinion of the majority. Blind imitation of peers can particularly be seen in the stock market, and media coverage enforces this behavior (Nofsinger, 2011). In this regard especially TV and internet are relevant.

Belsky and Gilovich (2007) study herd behaviour of investors. According to the authors, investment funds achieved a return of $12.3 \%$ per year from 1984 to 1995 . However the average person who invested in a fund only achieved $6.3 \%$ per year in this time. The reason for the deviation between the average return of the funds and the actual return investors achieved is that investors do not hold investment funds permanently. Instead they change funds in order to maximize their return. Often the opposite happens: investors lower their return. Typically, they choose investment funds which did well in the recent past. Such funds are mostly very present in the media. Often those recent winners are overpriced in comparison to the market and future returns are below average. 
H6.1: Investors are influenced by other investors and are not independent in decision making.

H6.2: Herd Behavior decreases with the increasing experience, education level and gross annual income of a person.

\section{Empirical Analysis}

\subsection{Sample and Survey Process}

To test the hypotheses we conducted an online survey among individual investors. Participants of the survey are clients of Cortal Consors, an online bank. Clients were selected by the following criteria:

$>\quad$ they had to trade more than once a year.

$>\quad$ they had to own at least one securities account worth more than 10000 EURO.

$>\quad$ they were not allowed to have been contacted in the past 12 months by Cortal Consors.

$>\quad$ they had to have an email address and were not allowed to have an advertising block.

Persons who met these criteria were contacted by Cortal Consors. In the cover letter, clients were told that psychological aspects of stock selection would be analyzed and that the survey should take about five minutes. Altogether 1,300 clients were contacted; 161 did not start to answer the interview. Consequently the net sample amounts to 1,139. 890 individuals completed the survey. On average, participants were 52 years old; $93.7 \%$ were male and $6.3 \%$ were female. Participants did not receive any compensation.

The survey aims to test the mistakes described above. After some socio-demographic attributes, Self-Attribution Bias, Equity Home Bias, Endowment Effect, Anchoring, Representativeness and Herd Behavior are tested. The survey took place between Friday, July 22 to Monday, July 25 2011. During that period clients could select a point in time to participate. It was possible to interrupt the interview and continue it later. Participants needed about 5 minutes to answer the survey.

\subsection{Implementation of Analysis}

Table 1 demonstrates the statistical tests we conducted for the different hypotheses. For tests of significance levels are $0.1,0.05$ and 0.01 .

Table 1. Summary: Statistical Tests

\begin{tabular}{lll}
\hline Behavioral Biases & Hypotheses and Statistical Tests & \\
\hline Self-Attribution Bias & H1.1: Chi-Square Test of Independence & H1.2: Logistic Regression \\
Equity HomeBias & H2.1: One-Sample-T-Test & H2.2: Linear Regression \\
Endowment Effect & H3.1: Wilcoxon Rank-Sum Test & H3.2: Logistic Regression \\
Anchoring & H4.1: Wilcoxon Rank-Sum Test & H4.2: Logistic Regression \\
Representativeness & H5.1: Chi-Square Goodness of Fit-Test & H5.2: Logistic Regression \\
Herd Behavior & H6.1: Chi-Square Goodness of Fit-Test & H6.2: Logistic Regression \\
\hline
\end{tabular}

Table 2 shows the types of dependent and independent variables of the multivariate analysis. In the survey, education and income were modelled as ordinal categorical variables. Thus, for the multivariate analysis they were coded using dummy variables.

Table 2. Multivariate Analysis: Considered Dependent and Independent Variables

\begin{tabular}{|c|c|c|c|c|}
\hline \multirow[t]{2}{*}{ Analysis } & \multicolumn{3}{|c|}{ Types of Variables } & \\
\hline & Dependent Variable & & ndent Variat & \\
\hline Linear R. (Home Bias) & $\begin{array}{l}\text { Interval } \\
(\% \text { domestic stocks })\end{array}$ & $\begin{array}{l}\text { Interval } \\
\text { (Experience) }\end{array}$ & $\begin{array}{l}\text { Dummy } \\
\text { (Educat.) }\end{array}$ & $\begin{array}{l}\text { Dummy } \\
\text { (Income) }\end{array}$ \\
\hline Logistic Regression & $\begin{array}{l}\text { Binary } \\
\text { (1 if Bias, } 0 \text { otherwise) }\end{array}$ & $\begin{array}{l}\text { Interval } \\
\text { (Experience) }\end{array}$ & $\begin{array}{l}\text { Dummy } \\
\text { (Educat.) }\end{array}$ & $\begin{array}{l}\text { Dummy } \\
\text { (Income) }\end{array}$ \\
\hline
\end{tabular}




\subsection{Statistical Results}

Hypothesis H1.1 assumes that investors attribute good results to their own abilities whereas bad results are attributed to bad luck. The relation between portfolio performance and investors' explanations for the performance is illustrated in the crosstabulation.

Table 3. Self-Attribution Bias: Crosstabulation

\begin{tabular}{clllllll}
\hline \multicolumn{1}{l}{ Performance Portfolio } & \multicolumn{1}{l}{} \\
\hline & Reason & Much Better & Better & Identical & Worse & Much Worse & Sum \\
\hline \multirow{4}{*}{ Destiny } & 0 & 9 & 17 & 21 & 0 & 47 \\
& Both & 40 & 245 & 284 & 136 & 20 & 725 \\
& Own Abilities & 7 & 45 & 41 & 23 & 2 & 118 \\
Sum & 47 & 299 & 342 & 180 & 22 & 890 \\
\hline
\end{tabular}

The crosstabulation shows that the predicted relation exists in the sample. To test whether this relation also holds true for the population we calculate a Chi-Square-Test of Independence. Moreover we use a correlation coefficient to test the direction and strength of the relation.

The Chi-Square-Test of Independence is significant at the 0.01-level (Chi-Square $=23.28[d f=8] ; p=0.003$ ). Therefore variables are not independent. Spearman's rank correlation coefficient is significant at the 0.01-level $(r=-0.91 ; p=0.007)$. Thus variables are negatively correlated. Investors tend to attribute good results to their own abilities whereas they attribute bad results to external factors. However it has to be put in perspective that three cells have a frequency of less than five. Therefore the explanatory power of the test is limited and results have to be interpreted with caution.

H1.2 states that the Self-Attribution Bias decreases with increasing experience, education level and gross annual income. To test whether those characteristics influence the probability that a person acts according to the Self-Attribution Bias we conduct a logistic regression.

$$
\begin{aligned}
& p_{k}(y=1)=\frac{1}{1+e^{-z_{k}}} \\
& z_{k}=\beta_{0}+\sum_{j=1}^{J} \beta_{j} x_{j}
\end{aligned}
$$

The dependent variable $\mathrm{p}_{\mathrm{k}}$ is the probability that a person acts according to the Self-Attribution Bias. 1 means Self-Attribution Bias, 0 means no Self-Attribution Bias. We assume an individual to be subject to the Self-Attribution Bias if he or she attributes positive performance solely to own abilities or negative performance solely to bad luck. $\beta_{0}$ is a constant and $\beta_{\mathrm{j}}$ are regression coefficients which are calculated by the logistic regression. $\mathrm{x}_{\mathrm{j}}$, is the independent variable experience, education level or gross annual income. We compute regression coefficients with a significance-test. Therefore we use the Wald-statistic.

\begin{tabular}{|c|c|c|c|c|c|c|}
\hline & Regression & Standard & & & & \\
\hline & Coefficient & Error & Wald & df & Sig. & $\operatorname{Exp}(B)$ \\
\hline Experience & .001 & .003 & .036 & 1 & .849 & 1.001 \\
\hline Education & -.394 & .162 & 5.888 & 1 & .015 & .675 \\
\hline Income & .047 & .164 & .082 & 1 & .774 & 1.048 \\
\hline (Constant) & -.432 & .144 & 9.024 & 1 & .003 & .649 \\
\hline Pseudo $\mathrm{R}^{2}$ & 0.011 & & & & & \\
\hline Observations & 890 & & & & & \\
\hline
\end{tabular}

Table 4. Self-Attribution Bias: Multivariate Test

The estimated regression equation is shown below:

$$
p_{\text {SelfAtt }}=\frac{1}{1+e^{-\left(-0.432+0.001 x_{\text {exp }}-0.394 x_{\text {edu }}+0.047 x_{\text {income }}\right)}}
$$


According to the Wald-statistic the only variable which is significantly different from zero is education. It has statistically significant predictive power for the probability that a person acts according to the Self-Attribution Bias at the 0.01-level. The minus sign in front of the regression coefficient for education shows that a higher education level means a lower probability that a person acts according to the Self-Attribution Bias. Correspondingly a lower education level means that the probability a person acts according to the Self-Attribution Bias is higher. The variables for experience and income are not significant.

Hypothesis H2.1 is tested with a One-Sample T-Test. We analyze whether the percentage of domestic stocks German investors choose is significantly different from the actual percentage of German stocks in the MSCI World index. The actual percentage of German stocks in the MSCI World index is $4.06 \%$ (Handelsblatt, 2011).

The arithmetic mean of domestic stocks German investors choose is $54.77 \%$. This is a difference of $50.71 \%$ to the test value of $4.06 \%$. This difference between the arithmetic mean and the test value is significant at the 0.01 -level $(T=64.46[d f=889] ; p<0.001)$. The alternative hypothesis is therefore assumed to be true. It could be confirmed that German investors overweight domestic stocks.

Hypothesis H2.2 postulates that the Equity Home Bias decreases with increasing experience, education level and income. To test the hypothesis we compute a linear regression. We analyze how the characteristics experience, education level and income influence the Equity Home Bias.

$$
y=\beta_{0}+\sum_{j=1}^{J} \beta_{j} x_{j}
$$

The dependent variable $y$ is the percentage of German stocks a person chooses, $\beta_{0}$ is a constant and $\beta_{\mathrm{j}}$ are regression coefficients calculated by the regression. $x_{j}$ are independent variables experience, education level and income.

Table 5. Equity Home Bias: Multivariate Test

\begin{tabular}{llllll}
\hline & Regression Coefficient & Standard Error & Beta & T & Sig. \\
\hline (Constant) & 56.633 & 1.483 & & 38.182 & .000 \\
Experience & -.022 & .035 & -.021 & -.621 & .535 \\
Education & -1.417 & 1.653 & -.030 & -.857 & .392 \\
Income & -1.597 & 1.680 & -.033 & -.951 & .342 \\
\hline $\mathrm{R}^{2}$ & 0.003 & & & & \\
Observations & 890 & & & & \\
\hline
\end{tabular}

The estimated equation is shown below:

$$
y=56.633-0,022 x_{\text {exp }}-1.417 x_{\text {edu }}-1.597 x_{\text {income }}
$$

As shown in table 5 none of the regression coefficients is significant. Therefore it is not acceptable to draw conclusions from the sample to the population.

Hypothesis H3.1 states that investors value an object more highly if they own it than if they do not. This hypothesis is tested with a Wilcoxon Rank-Sum Test because requirements for a T-Test are not met. To study the Endowment Effect, participants were faced with two questions: the first question asks if they would sell a dresser worth 500 Euro for 500 Euro which they bought for 200 Euro two years ago. The second question asks if they would buy the same dresser if they did not own it.

Table 6. Endowment Effect: First Question

\begin{tabular}{lll}
\hline & Frequency & Percentage \\
\hline Yes & 287 & 32.2 \\
No & 603 & 67.8 \\
Sum & 890 & 100.0 \\
\hline
\end{tabular}


Table 7. Endowment Effect: Second Question

\begin{tabular}{lll}
\hline & Frequency & Percentage \\
\hline Yes & 226 & 25.4 \\
No & 664 & 74.6 \\
Sum & 890 & 100.0 \\
\hline
\end{tabular}

Table 6 shows that $32.2 \%$ of the participants answered the first question with YES and $67.8 \%$ with NO. The second question was answered with YES by $25.4 \%$ and with NO by $74.6 \%$. To interpret these figures one has to consider that the questions are inversed: the second question asks about the willingness to buy the dresser; the first question asks about the willingness to sell the dresser. A person answering the second question with YES acts consistently with a person answering the first question with $\mathrm{NO}$ and vice versa. With the Wilcoxon Rank-Sum Test we analyze whether evaluations differ significantly.

The Wilcoxon-Test is significant at 0.01 -level. $(Z=-17.87 ; p<0.001)$. Hypothesis H3.1 is assumed to be true. The null hypothesis is rejected.

H3.2 states that the Endowment Effect decreases with increasing experience, education level and gross annual income. We conduct a logistic regression to analyse how those characteristics influence the probability that a person acts according to the Endowment Effect. Again we use the Wald-statistic to test whether regression coefficients are significant.

Table 8. Endowment Effect: Multivariate Test

\begin{tabular}{lllllll}
\hline & Regression Coefficient & Standard Error & Wald & df & Sig. & $\operatorname{Exp}(\mathrm{B})$ \\
\hline Experience & .000 & .003 & .000 & 1 & .999 & 1.000 \\
Education & -.098 & .141 & .486 & 1 & .486 & .906 \\
Income & -.010 & .144 & .005 & 1 & .944 & .990 \\
(Constant) & -.094 & .127 & .556 & 1 & .456 & .910 \\
\hline Pseudo R & 2 & 0.001 & & & & \\
Observations & 890 & & & & & \\
\hline
\end{tabular}

The estimated regression equation is shown below:

$$
p_{\text {Endow }}=\frac{1}{1+e^{-\left(-0.094-0.000 x_{\text {exp }}-0.098 x_{\text {edu }}-0.010 x_{\text {income }}\right)}}
$$

$\mathrm{p}_{\text {Endow }}$ is the probability that a person acts in line with the Endowment Effect. We suppose someone to act according to the Endowment Effect if he or she answers both the first and the second question with No. As shown in table 8 , no regression coefficient is significant.

Hypothesis H4.1 states that investors are influenced by irrelevant information. To test this hypothesis we ask participants to estimate the distances between Boston - New York City - Munich and Sydney - Tokyo Shanghai. The anchors we use in this study are two distances which had been mentioned before participants estimated the exact distances. The first anchor $(10000 \mathrm{~km})$ refers to the distance Boston - New York City Munich and the second anchor $(5000 \mathrm{~km})$ refers to the distance Sydney - Tokyo - Shanghai. In fact, the first distance is shorter than the second one (The distance Boston - New York City - Munich is only $6769 \mathrm{~km}$; the distance Sydney - Tokio - Shanghai is $9580 \mathrm{~km}$ ).

Table 9 shows that the mean guess for the first distance is $9463 \mathrm{~km}$ which is longer than the mean guess for the second distance. The mean guess for the second distance is only $8570 \mathrm{~km}$. The fact that people give a higher estimate for the first distance than for the second distance gives a first hint that people are influenced by the given anchors. Inferential statistics are used to test if results are valid for the population. 
Table 9. Anchoring: First Distance

\begin{tabular}{lll}
\hline & $\mathrm{N}$ & Mean \\
\hline Boston-New York City-Munich & 890 & 9463.31 \\
\hline
\end{tabular}

Table 10. Anchoring: Second Distance

\begin{tabular}{lll}
\hline & N & Mean \\
\hline Sydney-Tokyo-Shanghai & 890 & 8570.92 \\
\hline
\end{tabular}

Because requirements for a Dependent-T-Test are not met we calculate a Wilcoxon Rank-Sum Test. The Wilcoxon-Test is significant at 0.01 -level. $(Z=-6.44 ; p<0.001)$ Thus the alternative hypothesis H5 is assumed to be true.

H4.2 states that Anchoring declines with increasing experience, education level and gross annual income of a person. We conduct a logistic regression to test how those characteristics influence the probability that a person anchors. Again we use the Wald-statistic to test whether regression coefficients are significant.

Table 11. Anchoring: Multivariate Test

\begin{tabular}{lllllll}
\hline & Regression Coefficient & Standard Error & Wald & df & Sig. & Exp(B) \\
\hline Experience & .002 & .003 & .347 & 1 & .556 & 1.002 \\
Education & -.390 & .148 & 6.921 & 1 & .009 & .677 \\
Income & -.360 & .147 & 5.999 & 1 & .014 & .697 \\
(Constant) & .851 & .137 & 38.751 & 1 & .000 & 2.343 \\
\hline Pseudo R ${ }^{2}$ & 0.027 & & & & & \\
Observations & 890 & & & & \\
\hline
\end{tabular}

The estimated regression equation is shown below:

$$
p_{\text {anchor }}=\frac{1}{1+e^{-\left(0.851+0.002 x_{\text {exp }}-0.390 x_{\text {edu }}-0.360 x_{\text {income }}\right)}}
$$

$p_{\text {anchor }}$ describes the probability that a person acts according to Anchoring. A person is classified as prone to Anchoring if the person's estimate for the first distance exceeds the estimate for the second distance. The regression coefficient for education is significant at the 0.01-level. The regression coefficient for income is significant at the 0.05 -level. Both variables education and income have statistically significant predictive power for the probability that a person acts according to anchoring. The minus signs in front of the regression coefficients for education and income show that a higher education level and a higher income are accompanied by a lower probability that a person acts according to Anchoring. Correspondingly, a lower education level and a lower income implicate that the probability of a person acting according to Anchoring increases. The coefficient for experience is not significant.

Hypothesis H5.1 states that investors misjudge probabilities because they use Representativeness. In the survey, participants were asked on which outcome they would bet 10 Euro in a coin toss. They were told that before the toss, the coin was already tossed two times and in both tosses the result was tails. In a Chi-Square Goodness of Fit-Test we test whether the observed results for the answers heads and tails differ significantly from expected results for heads and tails. Expected answers for heads and tails are equally distributed.

The Chi-Square Goodness of Fit-Test is significant at the 0.01-level (Chi-Quadrat=168.01 $[d f=1] ; p<0.001)$. The null hypothesis has to be rejected and the alternative hypothesis H5.1 is assumed to be true.

H5.2 states that Representativeness decreases with higher experience, education level and gross annual income of a person. We calculate a logistic regression to test how those characteristics influence the probability that a person uses Representativeness. The Wald-statistic is used to analyze whether regression coefficients are significant. 
Table 12. Representativeness: Multivariate Test

\begin{tabular}{lllllll}
\hline & Regression coefficient & Standard error & Wald & df & Sig. & Exp(B) \\
\hline Experience & .003 & .003 & 1.142 & 1 & .285 & 1.003 \\
Education & -.674 & .149 & 20.530 & 1 & .000 & .510 \\
Income & .148 & .153 & .933 & 1 & .334 & 1.159 \\
(Constant) & -.374 & .129 & 8.437 & 1 & .004 & .688 \\
\hline Pseudo R & & & & & & \\
Observations & 0.033 & & & & & \\
\hline
\end{tabular}

Below the estimated regression equation is shown:

$$
p_{\text {repr }}=\frac{1}{1+e^{-\left(-0.374+0.003 x_{\text {exp }}-0.674 x_{\text {edu }}+0.148 x_{\text {income }}\right)}}
$$

$\mathrm{p}_{\text {repr }}$ stands for the probability that an individual acts according to Representativeness. A person is assumed to tend to Representativeness if he or she shows a preference for heads. The regression coefficient for education is significantly different from zero at the 0.01-level. It has statistically significant predictive power for the probability that a person uses Representativeness. The minus sign in front of the regression coefficient for education shows that a higher education level means a lower probability of using Representativeness. Accordingly a lower education level means that the probability that a person uses Representativeness is depressed. Coefficients for experience and income are not significant.

H6.1 states that investors are influenced by other investors and do not decide independently.

Participants were asked whether a friend selling stocks would influence their investment decision. To test the hypothesis a Chi-Square Goodness of Fit-Test is calculated. It is analyzed if observed frequencies differ significantly from expected frequencies. For the answers "Positive, I would now rather buy the stock" and "Negative, I would now rather stay away from the stock" identical frequencies are expected.

In fact $14.9 \%$ of participants chose answer "Negative, I would now rather stay away from buying the stock" whereas only $2.1 \%$ chose "Positive, I would now rather buy the stock." $82.9 \%$ opted for "Neutral. My friend's behavior would not influence my choice."

The Chi-Square Goodness of Fit-Test is significant at the 0.01-level. (Chi-Square $=85.50[d f=1] ; p<0.001$ ) Hypothesis H6.1 is assumed to be true: Investors are influenced by other investors and do not decide independently.

H6.2 states that herd behavior declines with rising experience, education level and gross annual income of a person. A logistic regression is calculated to test how those characteristics influence the probability that a person herds. The Wald-statistic is used to analyze whether regression coefficients are significant.

Table 13. Herd Behavior: Multivariate Test

\begin{tabular}{lllllll}
\hline & Regression Coefficient & Standard Error & Wald & df & Sig. & Exp(B) \\
\hline Experience & -.022 & .009 & 6.074 & 1 & .014 & .978 \\
Education & .053 & .199 & .070 & 1 & .791 & 1.054 \\
Income & .179 & .199 & .817 & 1 & .366 & 1.197 \\
(Constant) & -1.417 & .223 & 40.406 & 1 & .000 & .242 \\
\hline Pseudo R ${ }^{2}$ & 0.020 & & & & & \\
Observations & 889 & & & & & \\
\hline
\end{tabular}

The estimated regression equation is shown below:

$$
p_{\text {herd }}=\frac{1}{1+e^{-\left(-1.417-0.022 x_{\text {exp }}+0.053 x_{\text {edut }}+0.179 x_{\text {income }}\right)}}
$$

The probability that a person acts in line with Herd Behavior is expressed by pherd. We assume a person to act according to Herd Behavior if the person announces that in the explained situation he or she would rather stay away from buying the stock. The coefficient for experience is significantly different form zero at the 0.05 -level. It has statistically significant predictive power for the probability that a person herds. The fact that the regression 
coefficient of the variable experience is negative shows that a higher education level means a lower probability of herding. Accordingly a lower education level means that the probability a person herds is depressed. Regression coefficients for education and income are not significant.

\section{Discussion}

The study confirms Self-Attribution Bias. Results are in line with those of Choi and Dong (2008) and also Doukas and Petmezas (2007). Self-Attribution Bias can be particularly problematic in times of rising stock prices. The higher the prices soar the more investors typically tend to act according to Self-Attribution Bias because they regard rising stock prices as a personal success. This can lead investors to buy near the peak of the market because they are overly optimistic in those times.

A limitation of the study is that participants did not have to choose between destiny (good luck or bad luck) and own abilities (own skills or inability) in the survey. Therefore the fraction of participants which can be completely attributed to either destiny or own abilities is relatively low. Thus relevant parameter values are reduced considerably which makes the result less significant. In methodically similar studies this problem should be considered. A further limitation of the study is that investment performance could not be rechecked. It is possible that participants did not know the performance of their portfolio. A direct inspection of portfolio returns would probably have resulted in more reliable results.

We find that participants act according to the Equity Home Bias. Investors could lower their risk by lowering the fraction of German stocks. Risk which is due to incomplete diversification is unsystematic risk. Unsystematic risk is not compensated according to prevalent financial market models.

Findings confirm the results of Strong and Xu (2003) who find an Equity Home Bias for investors in the USA, Japan and Europe. Lütje and Menkhoff (2004) find an Equity Home Bias for institutional investors in Germany. However according to Lütje and Menkhoff (2004) institutional investors choose a smaller fraction of domestic stocks (11.8\%) than individual investors in this study. Therefore it seems to be particularly important to educate individual investors about the bias. This could diminish unnecessary risk which exists because of insufficient diversification.

The choice of an adequate benchmark index was problematic. The MSCI World index does not include every country of the World. Instead the index only contains 23 developed countries. Emerging Markets are not included in the MSCI World index. Small stocks are not included in the MSCI World index, either. Therefore the MSCI World index is not a perfect benchmark. However if countries not represented by the MSCI World index were included, results would be even clearer and more significant. An alternative is the less known MSCI All Country World index which also incorporates developing countries. However a weakness of the MSCI All Country World index is that some large countries appear to be underrepresented. In the MSCI All Country World index the German market has a weight of about 3.2\%. Therefore, the use of this index as a benchmark would lead to an even clearer and more significant result because German stocks have a smaller fraction than within the MSCI World Index. (Financial Times Deutschland, 2011).

Results confirm the Endowment Effect for German investors. They are in line with the findings of Samuelson and Zeckhauser (1988). Obviously the Endowment Effect can affect investor behavior negatively. However the Endowment Effect also brings about some benefits for investors: transaction costs are reduced because of lower trading frequency.

Whereas the Endowment Effect in general is confirmed, the temporal development of the Endowment Effect is not analyzed. It would be interesting to know whether the Endowment Effect increases with the length of time an investor holds stocks. Future studies could answer this question. Moreover H3.1 does not test how individuals behave in a stock market situation. Therefore, the question is whether investors act accordingly in such a situation.

We confirm Anchoring for German investors. Results are in line with those of Tversky and Kahnemann (1974). However an essential difference is that participants in the Tversky and Kahneman study assumed that the figure which served as an anchor was generated by chance.

In practice a typical anchor which influences investors in deciding whether to sell a stock is the purchasing price. Obviously this price should not play a role for rational individuals. Nevertheless investors often hold stocks which are priced below the purchasing price because they do not want to realize a loss. Stocks which are priced higher than the buying price are often sold to realize a gain. This orientation to the purchasing price is irrational.

Representativeness is assumed to be true. A major fraction of participants obviously think that after a series of heads the probability for tails rises because heads and tails are uniformly distributed in a large number of entities. 
This idea seems to influence the behavior of participants. In fact, in every coin toss the probability for heads is the same as the probability for tails.

In practice Representativeness plays an important role in financial markets. According to Lakonishok, Shleifer and Vishny (1994), investors often mistake good companies for good investments. They typically extrapolate high growth rates of the past into the future. When investors systematically assume an earnings growth rate which is too high, growth stocks can become overvalued. Lakonishok et al. (1994) conclude that growth stocks earned a significantly lower return than value stocks in the period form 1963 to 1990. They attribute this finding to overvaluation of growth stocks. Lakonishok et al. (1994) use the term value stocks for stocks which had a below average growth rate of earnings as well as low multiples and growth stocks for stocks which had an above average growth rate of earnings as well as high multiples.

H6.1 is assumed to be true. Investors are influenced by other investors. This can lead to a consensus. Herding means that individuals act according to the consensus (Nofsinger, 2011), and in financial markets herding can cause overreactions (Shiller, 2005). Hence differences between price and intrinsic value of equities are possible. Such imbalances have to disappear over time. Adjustments can impact the real economy, especially if adjustments happen very suddenly the effects are often severe (Shiller, 2005). Heavy fluctuations can influence the economic development and employment of a country. Because of global interrelations foreign markets are affected, too. A main future challenge of behavioral research is to identify bubbles in financial markets in order to warn policy makers.

In comparison to other studies this study does not analyze mass dynamics associated with herd behavior. Instead we only test if one individual is influenced by another individual. A limitation of the study is that answers of participants do not necessarily have to match actual behavior.

Table 14. Overview Multivariate Tests: Regression Coefficients

\begin{tabular}{llll}
\hline & Experience & Education & Income \\
\hline Self-Attribution Bias & 0.001 & $-0.394^{* * *}$ & 0.047 \\
Equity-Home Bias & -0.022 & -1.417 & -1.597 \\
Endowment Effect & 0.00 & -0.098 & -0.01 \\
Anchoring & 0.002 & $-0.39 * * *$ & $-0.36^{* *}$ \\
Representativeness & 0.003 & $-0.674^{* * *}$ & 0.148 \\
Herd Behavior & $-0.022^{* *}$ & 0.053 & 0.179 \\
\hline
\end{tabular}

Table 14 gives a summary of the main findings of multivariate analysis. It reports regression coefficients for different regression equations. $*$ indicates statistical significance at the 0.1 -level, ${ }^{* *}$ at the 0.05 -level and $* * *$ at the 0.01-level. Regarding socio-demographic characteristics which impact behavior, three regression coefficients are significant at the 0.01-level and two more are significant at the 0.05 -level. All of these significant coefficients affect investor behavior with their predicted signs. In other words, all significant variables are negative: higher education leads to a lower probability that a person acts according to the Self-Attribution Bias; higher education and a higher income lead to a lower probability that a person acts according to Anchoring; higher education leads to a lower probability that a person acts according to Representativeness and more experience leads to a lower probability that a person herds. Yet, it must be emphasized that most independent variables are not significant according to the Wald test. The most predictive independent variable is education. Education influences three dependant variables at the 0.01-level of significance: Self-Attribution Bias, Anchoring and Representativeness. Experience and income influence the probability of one dependant variable each but only at the 0.05-level. Experience influences Anchoring and income influences Herd Behavior. It stands out that education is the most important socio demographic attribute.

Irrational investor behavior causes both individual and macroeconomic damage as demonstrated by the recent financial crisis. Therefore it is crucial to prevent misbehavior. As shown in the study education plays an important role in protecting investors. Thus in order to get an efficient stock market educated investors are needed.

\section{References}

Asch, S. (1952). Social Psychology. New Jersey: Prentice Hall, 450-500. http://dx.doi.org/10.1037/10025-016

Belsky, G., \& Gilovich, T. (2007). Das Lemmingprinzip. Munich: Finanzbuch Verlag. 
Chan, K., Covrig, V., \& Ng, L. (2005). What Determines the Domestic Bias and Foreign Bias? Evidence from Mutual Fund Equity Allocation Worldwide. Journal of Finance, 60, 1495-1534. http://dx.doi.org/10.1111/j.1540-6261.2005.768_1.x

Choi, D., \& Dong, L. (2008). A test of the self-serving attribution bias: evidence from mutual funds. Working paper, Hong Kong University of Science and Technology.

Deutsches Aktieninstitut. (2011). http://www.dai.de/internet/dai/dai-2-0.nsf/dai_publikationen.htm

Doukas, J., \& Petmezas, D. (2007). Acquisitions, Overconfident Managers and Selfattribution Bias. European Financial Management, 13(3), 531-577. http://dx.doi.org/10.1111/j.1468-036X.2007.00371.x

Financial Times Deutschland. (2011). MSCI World ist Anachronismus. http://www.ftd.de/finanzen/maerkte/:portfolio-msci-world-ist-anachronismus/50214798.html

Handelsblatt. (2011). Emerging Markets schlagen den Rest der Welt. http://www.handelsblatt.com/finanzen/zertifikate/nachrichten/emerging-markets-schlagen-den-rest-der-welt $-/ 4346232 . h t m l$

He, W., \& Shen, J. (2009). Extrapolation Bias and Investors Expectations. AFAANZ Conference, Adelaide.

Heath, C., \& Tversky, A. (1991). Preferences and Beliefs: Ambiguity and Competence in: Choice Under Uncertainty. Journal of Risk and Uncertainty, 4, 5-28. http://dx.doi.org/10.1007/BF00057884

Huberman, G. (2001). Familiarity Breeds Investment. Review of Financial Studies, 14, 659-680. http://dx.doi.org/10.1093/rfs/14.3.659

Kahneman, D., Knetsch, J., \& Thaler, R. (1991). Experimental Test of the endowment effect and the Case Theorem. Journal of Political Economy, 98, 1325-1348. http://dx.doi.org/10.1086/261737

Kang, J. K., \& Stulz, R. (1997). Why is There a Home Bias? An Analysis of Foreign Portfolio Equity Ownership in Japan. Journal of Financial Economics, 46, 3-28. http://dx.doi.org/10.1016/S0304-405X(97)00023-8

Lakonishok, J., Shleifer, A., \& Vishny, R. (1994). Contrarian Investment, Extrapolation, and Risk. Journal of Finance, 48, 1541-1578.

Lau, R., \& Russell, D. (1980). Attributions in the sports pages. Journal of Personality and Social Psychology, 39, 29-38. http://dx.doi.org/10.1037/0022-3514.39.1.29

Li, K. (2004). Confidence in the Familiar: An international Perspective. Journal of Financial and Quantitative Analysis, 39, 47-68. http://dx.doi.org/10.1017/S0022109000003884

Lütje, T., \& Menkhoff, L. (2004). What Drives Home Bias? Evidence from Fund Managers Views. Working Paper, University of Hannover.

Markowitz, H. (1952). Portfolio Selection. Journal of Finance, 7, 77-91.

Milgram, S (1974). Obedience to Authority. New York: Harper Perennial.

Miller, D., \& Ross, M. (1975). Self-serving biases in the attribution of causality: Fact or fiction? Psychological Bulletin, 82(2), 213-225. http://dx.doi.org/10.1037/h0076486

Nofsinger, J. (2011). The Psychology of Investing, Boston: The Prentice Hall Series in Finance.

Samuelson, W., \& Zeckhauser, R. (1988). Status Quo Bias in Decision Making. Journal of Risk and Uncertainty, 1, 7-59. http://dx.doi.org/10.1007/BF00055564

Shiller, R. (2005). Irrational Exuberance. Princeton: Princeton University Press.

Strong, N., \& Xu, X. (2003) Understanding The Equity Home Bias: Evidence form Survey Data. Review of Economics and Statistics, 85, 307-312. http://dx.doi.org/10.1162/003465303765299837

Thaler, R. (2005). Advances in Behavioral Finance, 2. Princeton: Princeton University Press.

Tversky, A., \& Kahneman, D. (1974). Judgment under uncertainty: Heuristics and biases. Science, 185, 1124-1130. http://dx.doi.org/10.1126/science.185.4157.1124 